\title{
Avaliação morfológica e imuno-histoquímica de linfomas gástricos primários
}

\section{Morphologic and immunohistochemical evaluation of primary gastric lymphomas}

Jorge Alberto Thomé1; Agnes Cristina Fett-Conte²; José Antonio Cordeiro³

uniterm
Estômago
Linfoma
p53
BCL-2
BCL-6
MALT
Imuno-histoquímica

\section{resumo}

Introdução: Os linfomas gástricos primários representam cerca de 50\% dos linfomas não-Hodgkin extranodais e de $2 \%$ a $8 \%$ das neoplasias malignas do estômago. A maioria é formada pela proliferação de linfócitos $B$, que ocorre a partir do tecido linfóide associado à mucosa. Esse tecido, inexistente no estômago em condições normais, surge como conseqüência de gastrite crônica, na maioria das vezes associada à bactéria Helicobacter pylori. A inflamação crônica provocada pela infecção bacteriana parece sensibilizar linfócitos $T$, levando a estímulo constante de linfócitos $B$, que passam a proliferar inicialmente em padrão reacional. Posteriormente surgem alterações genômicas nessas células, que provocam ganho proliferativo, seleção clonal e transformação neoplásica, dando origem a linfoma de baixo grau. Alterações genéticas adicionais, como mutações em p53, podem induzir transformação para alto grau. Material e métodos: Foram estudados 32 casos de linfomas gástricos: 15 de baixo e 17 de alto grau. Foram investigados sexo e idade dos pacientes, características morfológicas das lesões, índice de proliferação celular e colonização pelo Helicobacter pylori. Verificou-se a expressão de CD20, Ki-67, p53, BCL-2 e BCL-6 por imuno-histoquímica. Resultados: Os linfomas gástricos ocorreram mais freqüentemente em homens, e a faixa etária mais elevada foi observada no grupo de baixo grau. Lesões linfoepiteliais foram observadas em $93 \%$ dos linfomas desse grupo. O índice de proliferação celular e a expressão do p53 foram mais elevados no grupo de alto grau. A expressão do BCL-2 foi mais elevada nos linfomas de baixo grau. Não houve diferença significante quanto à expressão do BCL-6 nos dois grupos. Conclusão: Os resultados sugerem a participação dos genes p53 e BCL-2 na patogênese e na evolução dos linfomas gástricos.

abstract

Introduction: Primary gastric lymphomas account for $50 \%$ of the extranodal non-Hodgkin lymphoma and for $2 \%$ to $8 \%$ of the malignant gastric neoplasms. Most of them arise from B lymphocytes proliferation of the mucosaassociated lymphoid tissue. This tissue is not present in stomach in normal conditions; it arises secondarily to chronic gastritis, frequently associated to the bacterium Helicobacter pylori. Chronic inflammation of the bacterium infection seems to induce Tlymphocytes, leading to persistent stimulation of B lymphocytes that initially proliferate in a reactive fashion. After that, there are some genomic changes in the lymphoid cells, including BCL-2 and BCL-6 mutation inducing some proliferating gain, clonal selection and neoplastic transformation, originating the lowgrade gastric lymphoma. Additional genetic changes, like $p 53$ mutation, can induce high-grade transformation. Material and methods: We revised 32 cases of gastric lymphomas: 15 low and 17 high-grade. The age and the gender of those patients were investigated. The morphological characteristics of the lesions and Helicobacter pylori colonization were assessed. Immunohistochemistry to CD20, Ki-67, p53, BCL-2 and BCL-6 was performed. Results: Gastric lymphomas occur more frequently in males and patients' age is more advanced in the low grade group. Lymphoepithelial lesions were observed in 93\% of this lymphoma group. The proliferative rate and p53 expression were greater in the high grade group. The BCL-2 expression was higher in the low grade lymphoma group. There were no significant differences in BCL-6 expression in both groups. Conclusion: The results suggest that genes P53 and BCL-2 play a role in the pathogenesis and evolution of gastric lymphomas.

\section{key words}

Gastric lymphoma

MALT

p53

$B C L-2$

$B C L-6$

Immunohistochemistry

1. Professor-assistente do Departamento de Anatomia Patológica da Faculdade de Medicina de São José do Rio Preto (FAMERP).

2. Professora-adjunta do Departamento de Biologia Molecular da FAMERP.

3. Professor-coordenador de ensino do Departamento de Epidemiologia e Saúde Coletiva da FAMERP.

Trabalho baseado em dissertação de mestrado a ser apresentada na FAMERP, intitulada Caracterização Morfológica e Avaliação da Expressão Cênica por Imuno-Histoquímica em Linfomas Cástricos. Foi apresentado em seção de pôsteres do XXIV Congresso Brasileiro de Patologia, na cidade de Florianópolis (SC), em 2 de maio de 2003. 


\section{Introdução}

Os linfomas não-Hodgkin (LNH) extranodais representam cerca de $8 \%$ dos $\mathrm{LNH}$, sendo que a metade deles ocorre no estômago. Os linfomas gástricos primários (LG) constituem $2 \%$ a $8 \%$ das neoplasias malignas do órgão(25). São classificados em categorias de baixo e alto grau de acordo com o quadro histológico e evolução clínica ${ }^{(27)}$.

Os órgãos não-linfóides, particularmente o intestino, apresentam o chamado tecido linfóide associado à mucosa (MALT). Este é constituído basicamente pelas placas de Peyer, linfócitos da lâmina própria, linfócitos T intra-epiteliais e linfonodos mesentéricos, que parecem estar envolvidos na proteção da mucosa. Contudo, alguns órgãos que não contêm tecido linfóide em condições normais, como o estômago, a tireóide e as glândulas salivares, podem apresentálo em condições patológicas, particularmente nos processos inflamatórios. Nesses casos o infiltrado se denomina MALT adquirido. No estômago, o MALT adquirido é, na maioria das vezes, conseqüência de infecção pelo Helicobacter pylori e pode dar origem ao linfoma do tecido linfóide associado à mucosa ${ }^{(23)}$. Em até $90 \%$ dos casos, esse tipo de linfoma regride após a erradicação da infecção ${ }^{(34,38)}$.

Os linfomas gástricos de baixo grau do tipo MALT (LGBG) são formados pela proliferação de pequenos linfócitos que infiltram a mucosa e freqüentemente formam lesões linfoepiteliais. Apresentam crescimento lento e podem permanecer localizados no trato gastrintestinal por longo período de tempo ${ }^{(40)}$. Os linfomas gástricos de alto grau (LGAG) são principalmente linfomas difusos de grandes células $B$; são freqüentemente extensos, ulcerados e têm índice de proliferação celular elevado, sendo muitas vezes diagnosticados em estágios avançados ${ }^{(33)}$. A coexistência de dois componentes na mesma neoplasia pode ser indicativa de que os linfomas de alto grau podem se originar de linfomas de baixo grau previamente existentes(36).

Na patogênese dos LG parece ter importância a ocorrência de mutações em diversos genes ${ }^{(23)}$. Entre eles, destacam-se o gene BCL-2, envolvido na apoptose celular(28), o BCL-6, que participa na regulação da transcrição e o p53, um supressor de tumor envolvido na regulação da proliferação celular ${ }^{(9)}$.

Este estudo tem como objetivos verificar faixa etária, sexo, aspectos morfológicos, infecção pelo Helicobacter pylori (Hp), índice de proliferação celular (IP) e expressão dos genes BCL-2, BCL-6 e p53 por imuno-histoquímica em linfomas gástricos, comparando os resultados nos grupos de baixo e alto grau.

\section{Material e método}

Foram avaliados retrospectivamente 32 casos de linfomas gástricos primários, diagnosticados por biópsia endoscópica ou gastrectomia entre 1996 a 2002. Os casos foram classificados de acordo com a Revised European-American Classification of Lymphoid Neoplasms (REAL) ${ }^{(18)}$ e distribuídos em dois grupos. No primeiro, considerado de baixo grau, foram incluídos 17 casos de linfoma extranodal de células $B$ da zona marginal do tecido linfóide associado à mucosa (linfoma MALT). No segundo grupo, considerado de alto grau, foram incluídos 15 casos de linfoma difuso de grandes células. Foram realizados cortes histológicos no material previamente fixado em formol e incluído em parafina. A coloração de H\&E foi utilizada para avaliação morfológica e a de Giemsa, para pesquisa da bactéria Helicobacter pylori.

\section{Estudo imuno-histoquímico}

O anticorpo AE1/AE3 (DAKO, 1:50) foi utilizado para demonstração de lesões linfoepiteliais e CD20 (DAKO, 1:100), para imunofenotipagem dos linfomas. $O$ índice de proliferação celular (IP) foi avaliado semiquantitativamente pela expressão nuclear de Ki-67 (anticorpo monoclonal Novocastra NCL-Ki-67, diluição 1:200). Os casos foram subdivididos em dois grupos. No grupo 1, de IP baixo, foram incluídos os casos nos quais o número de células positivas foi menor que $25 \%$. No grupo 2, de IP alto, foram incluídos os casos com mais de $25 \%$ de células positivas. A expressão de p53 foi verificada utilizando-se anticorpo monoclonal DAKO na diluição de 1:100. Foram considerados positivos os casos com mais de $5 \%$ das células com núcleo corado. A proteína BCL-2 foi pesquisada pelo anticorpo monoclonal Novocastra, diluição 1:50. O critério de positividade foi a reatividade citoplasmática em mais de $5 \%$ das células neoplásicas. Para avaliação do BCL-6 foi usado anticorpo monoclonal produzido pela Novocastra, na diluição 1:40. Foram considerados positivos os casos com imunocoloração nuclear em $30 \%$ ou mais das células neoplásicas. A positividade em centros germinativos reacionais foi utilizada como controle interno.

Foram utilizados como controles três fragmentos de tonsila palatina, para avaliação da expressão dos oncogenes em tecido linfóide normal, e três fragmentos de mucosa gástrica obtidos por biópsia endoscópica com diagnóstico de gastrite crônica ativa, para controle positivo da pesquisa do Helicobacter pylori e avaliação da expressão dos oncogenes em processo inflamatório da mucosa gástrica. 
$\mathrm{Na}$ análise estatística foi utilizado teste para uma proporção para avaliação da significância do sexo, infecção pelo $H p$, presença de lesões linfoepiteliais e expressão de p53, BCL-2 e BCL-6. As variáveis idade, IP e expressão dos genes foram comparadas com o grau histológico, utilizando-se teste $t$ unicaudal. A associação entre variáveis qualitativas foi feita pelo teste qui-quadrado de Pearson.

\section{Resultados}

\section{Avaliação epidemiológica}

Dos 32 casos estudados, 22 (69\%) eram do gênero masculino e dez (31\%), do feminino $(p=0,025)$. Dos homens, 11 tinham LGBG e 11, LGAG. A idade dos pacientes foi em média de 64 anos nos linfomas de baixo grau e 56 anos nos de alto grau. Esses valores foram diferentes estatisticamente $(p=0,038)$.

\section{Avaliação morfológica}

Nos LGBG foi observada proliferação de pequenos linfócitos, por vezes com aparência monocitóide, entremeando-se raros plasmócitos. Os LGAG demonstraram proliferação difusa de grandes células linfóides, formadas por núcleos arredondados e nucléolos proeminentes. Em dez dos 17 casos de alto grau observou-se componente de baixo grau associado, em geral localizado perifericamente. Alguns casos apresentaram, ainda, alterações secundárias como erosões, ulcerações, hiperplasia foveolar e regeneração epitelial. Foram identificadas lesões linfoepiteliais (LLE) em 14 (93\%) dos LG de baixo grau e em oito (47\%) dos LG de alto grau, diferença estatisticamente significante ( $p$ $<0,01)$. Nos últimos, as LLE foram observadas no componente de baixo grau.

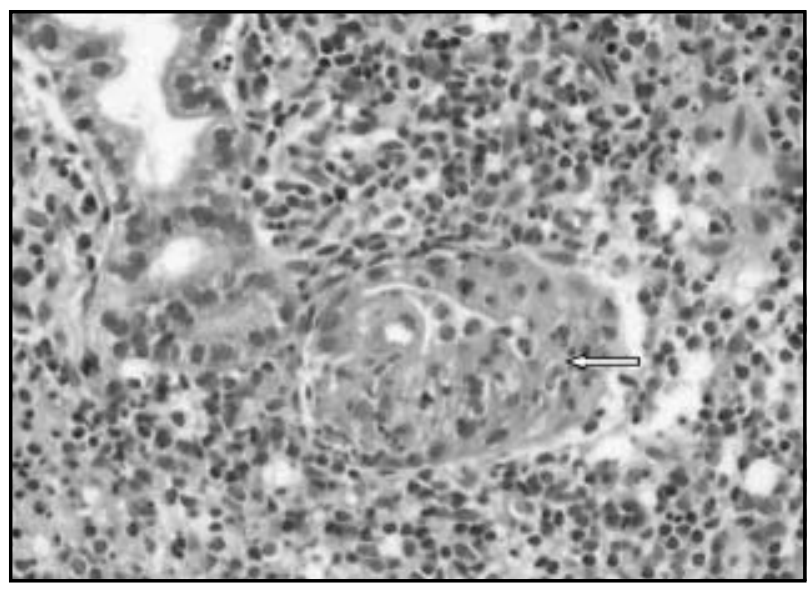

Figura 1 - Linfoma do tipo MALT (baixo grau) formado por linfócitos pequenos que infiltram glândulas formando lesões linfoepiteliais (HE 100x)

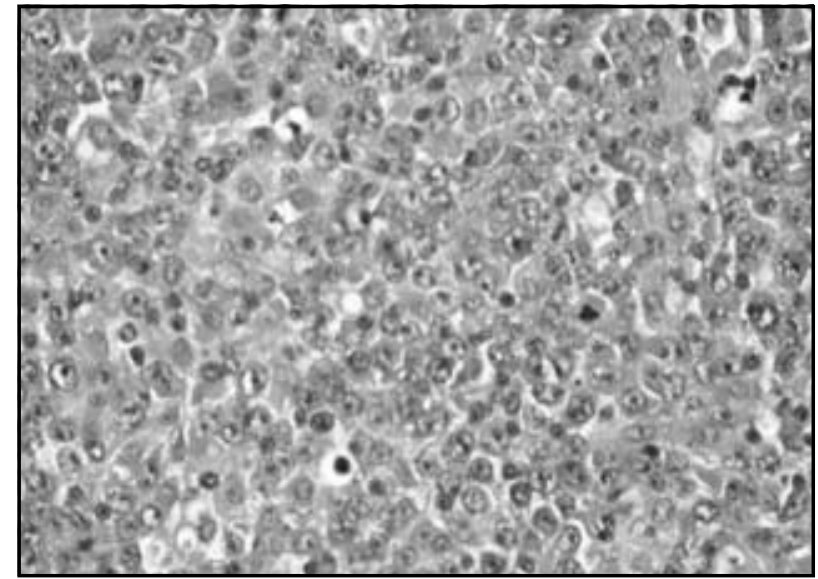

Figura 2 - Linfoma difuso de grandes células B (alto grau). Células predominantemente não-clivadas, com diferenciação centroblástica (HE 400x)

\section{Colonização por Helicobacter pylori}

A pesquisa do Helicobacter pylori foi positiva em dez (67\%) dos linfomas de baixo grau e em oito (47\%) dos de alto grau. $O$ estudo estatístico não demonstrou correlação entre grau histológico e infecção $(p=0,06)$.

\section{Índice de proliferação celular}

Dos LGBG, dez (67\%) apresentaram IP inferior a $25 \%$. Os LGAG apresentaram IP superior a 25\% em 15 (88\%) casos. Há associação positiva entre a expressão de Ki-67 e grau histológico $(p<0,01)$.

\section{Expressão dos genes p53, BCL-2 e BCL-6}

A proteína produto do gene $\mathrm{p} 53$ foi positiva em um (7\%) dos LGBG e em 13 (76\%) dos LGAG. A proteína BCL-2 foi expressa em 12 (80\%) dos LGBG e em cinco (29\%) dos LGAG. Nestes, a expressão de BCL-2 é observada em pequenos linfócitos do componente de baixo grau associado. A proteína BCL-6 foi positiva em quatro (27\%) dos LGBG e em sete $(41 \%)$ dos LGAG. Comparando-se a expressão desses genes nos dois grupos, observou-se diferença significante de p53 $(p<0,01)$, porém não houve diferença de BCL-2 $(p=0,29)$ e BCL-6 $(p=0,67)$. Houve relação inversa entre a expressão de $\mathrm{p} 53$ e BCL-2 $(p=0,004)$.

\section{Discussão}

Os linfomas gástricos (LG) apresentam particularidades na sua patogênese, apresentação morfológica e evolução clínica que os distinguem dos linfomas não-Hodgkin nodais. Uma das particularidades é a estreita relação desse tipo de neoplasia com a infecção pelo Helicobacter pylori ${ }^{(23,38)}$. 


\section{Tabela 1 Demonstrativo de todos os parâmetros avaliados neste trabalho}

\begin{tabular}{|c|c|c|c|c|c|c|c|c|c|c|}
\hline Cód. & Sexo & Idade & Grau & Hp & LLE & CD20 & Ki-67 & p53 & BCL-2 & BCL-6 \\
\hline $\mathrm{T} 1$ & $\mathrm{M}$ & 75 & B & + & + & + & 2 & - & + & + \\
\hline T2 & $\mathrm{M}$ & 73 & B & + & + & + & 1 & - & + & - \\
\hline T3 & $\mathrm{M}$ & 61 & $A^{*}$ & + & + & + & 1 & - & - & - \\
\hline T4 & $\mathrm{M}$ & 55 & $A^{*}$ & + & Prej. & + & 2 & + & - & - \\
\hline T5 & M & 75 & B & + & + & + & 2 & - & + & + \\
\hline T6 & $\mathrm{M}$ & 48 & $\mathrm{~A}^{*}$ & + & + & + & 2 & - & - & - \\
\hline T7 & $\mathrm{M}$ & 54 & $\mathrm{~A}$ & - & Prej. & - & 2 & + & - & - \\
\hline T8 & $\mathrm{F}$ & 55 & B & + & + & + & 1 & - & + & - \\
\hline T9 & $\mathrm{M}$ & 82 & B & - & + & + & 1 & - & + & - \\
\hline T10 & $\mathrm{F}$ & 88 & $\mathrm{~A}$ & - & Prej. & + & 2 & + & - & - \\
\hline T11 & $\mathrm{M}$ & 50 & $A^{*}$ & + & Prej. & + & 2 & + & - & + \\
\hline T12 & M & 73 & B & - & + & + & 1 & - & + & Prej. \\
\hline T13 & M & 54 & A & + & - & + & 2 & - & - & - \\
\hline T14 & $\mathrm{F}$ & 46 & B & + & + & + & 1 & - & + & + \\
\hline T15 & F & 48 & $\mathrm{~A}$ & + & + & + & 2 & + & + & + \\
\hline T16 & $\mathrm{M}$ & 52 & $A^{*}$ & - & + & + & 2 & + & - & - \\
\hline T17 & $\mathrm{M}$ & 62 & B & - & + & + & 1 & - & + & - \\
\hline T18 & F & 58 & $A^{*}$ & - & + & + & 2 & + & + & + \\
\hline T19 & F & 57 & $A^{*}$ & + & + & + & 2 & + & - & - \\
\hline T20 & F & 52 & $A^{*}$ & - & + & + & 2 & + & + & + \\
\hline T21 & M & 50 & $\mathrm{~A}$ & Prej. & Prej. & + & 2 & + & - & + \\
\hline T22 & $\mathrm{M}$ & 61 & B & + & + & + & 2 & + & - & + \\
\hline T23 & $\mathrm{M}$ & 63 & $A^{*}$ & + & + & + & 1 & - & + & - \\
\hline T24 & $\mathrm{M}$ & $\mathrm{NI}$ & $B$ & Prej. & Prej. & + & 1 & - & Prej. & Prej. \\
\hline T25 & $\mathrm{M}$ & 54 & $\mathrm{~A}$ & Prej. & Prej. & + & 2 & + & - & - \\
\hline T26 & $\mathrm{F}$ & 56 & B & Prej. & + & + & 1 & - & + & - \\
\hline T27 & M & 49 & $B$ & + & + & + & 1 & - & + & Prej. \\
\hline T28 & $\mathrm{M}$ & 63 & $A^{*}$ & Prej. & Prej. & + & 1 & + & + & + \\
\hline T29 & $\mathrm{M}$ & 83 & B & + & + & + & 1 & - & Prej. & - \\
\hline T30 & $\mathrm{M}$ & 54 & B & + & + & + & 2 & - & + & - \\
\hline T31 & $\mathrm{F}$ & 47 & $\mathrm{~A}$ & - & Prej. & + & 2 & + & - & + \\
\hline T32 & $\mathrm{F}$ & 64 & $\mathrm{~B}$ & + & + & + & 2 & - & + & - \\
\hline
\end{tabular}

A: alto grau; B: baixo grau; $A^{*}$ : alto grau com componente de baixo grau associado; Prej.: avaliação prejudicada; M: sexo masculino; F: sexo feminino; NI: não-informado; Cód.: código; +: resultado positivo; -: resultado negativo.

Tabela 2 Expressão de p53, BCL-2 e BCL-6 em linfomas gástricos primários

\begin{tabular}{lccc}
\hline & LGBG & LGAG & AE \\
p53 & $1(7 \%)$ & $13(76 \%)$ & $p<0,01$ \\
BCL-2 & $12(80 \%)$ & $5(29 \%)$ & $p=0,29$ \\
BCL-6 & $4(27 \%)$ & $7(41 \%)$ & $p=0,67$ \\
\hline
\end{tabular}

LGBG: linfoma gástrico de baixo grau; LGAG: linfoma gástrico de alto grau; AE: análise estatística comparativa da expressão nos linfomas de baixo e alto graus. 


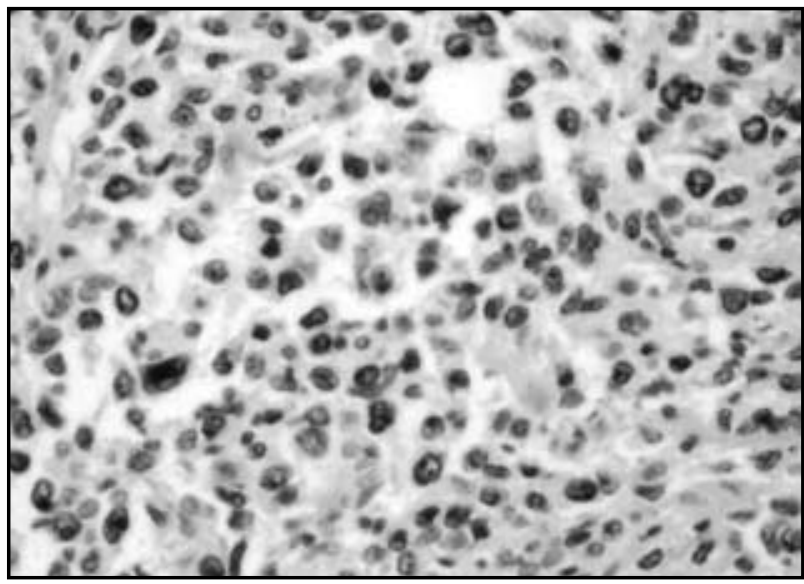

Figura 3 - Expressão da proteína Ki-67 em linfoma de alto grau. Mais de 50\% dos núcleos são positivos (Ki-67 400x)

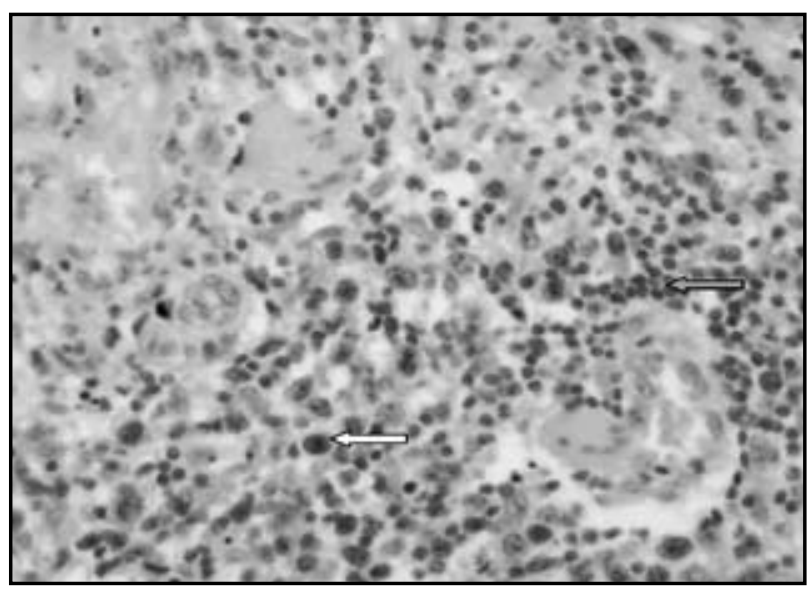

Figura 5 - Expressão da proteína p53 em núcleos de grandes células do componente de alto grau (seta clara) e ausência de expressão nas áreas de baixo grau (seta escura) (p53 400x)

Paradoxalmente, embora o estômago seja o local mais acometido por linfoma MALT, não se observa tecido linfóide no órgão em condições normais. Esse tecido surge em conseqüência de gastrite associada ao $H p$, que é identificada em até $90 \%$ dos casos de LG de baixo grau ${ }^{(39)}$, sugerindo uma ligação direta entre ambos ${ }^{(22)}$. Dados obtidos por estudos morfológicos, biologia molecular e em experimentos com animais têm mostrado que a infecção pelo $\mathrm{Hp}$ tem papel importante na patogênese e na progressão dos LG MALT ${ }^{(13,20)}$.

Outro forte indicativo da relação do linfoma MALT com o Hp é o fato de que o LG pode involuir com o tratamento da infecção ${ }^{(15,34,38)}$. Arima e Tsudo(3) observaram, também, regressão de linfoma do tipo MALT associado à tireoidite de Hashimoto, após tratamento de $\mathrm{Hp}$ em paciente com câncer gástrico. Os autores sugeriram que a bactéria pode estar implicada na patogênese de linfo-

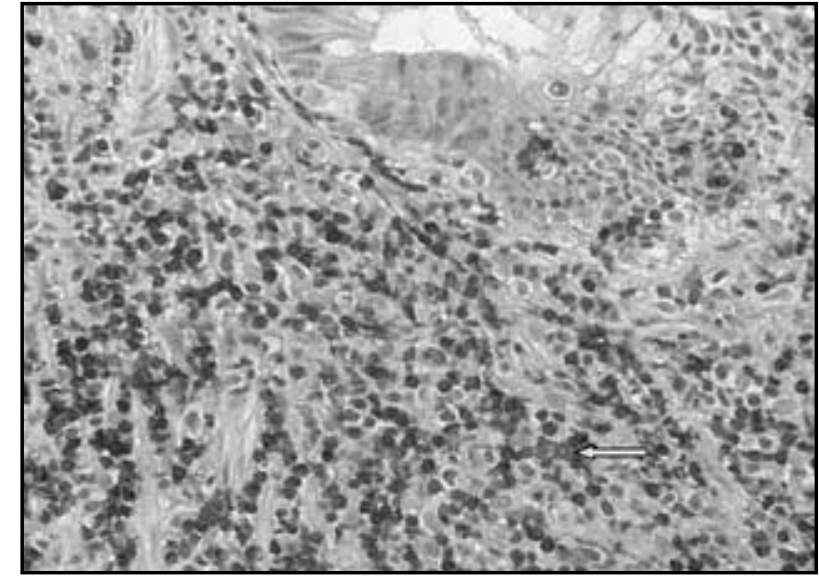

Figura 4 - Expressão de BCL-2 em componente de baixo grau (seta). Negativo em grandes células linfóides (BCL-2 100x)

mas MALT extragástricos, mesmo considerando que a pesquisa de Hp por PCR no linfoma da tireóide tenha sido negativa ${ }^{(6)}$. Também observaram regressão concomitante de linfoma MALT gástrico e laríngeo após erradicação do Hp e propuseram - para pacientes com linfomas MALT extragástricos - endoscopia digestiva com biópsia gástrica e posterior tratamento do $\mathrm{Hp}$, nos casos positivos. Neste estudo a média de idade dos pacientes com LGAG foi de 64,8 anos, enquanto que a média foi de 56,1 anos nos LGBG. A diferença é estatisticamente significante $(p=0,038)$ e demonstra que os LGBG ocorreram em pacientes mais velhos. Esse resultado é diferente do observado por Yoshino et al. ${ }^{(40)}$, que encontraram LGBG em pacientes mais novos. Tal inversão da faixa etária pode, supostamente, ser conseqüência de fatores patogenéticos regionais, ou ainda, devida a variações relacionadas ao tamanho amostral.

Foi observada uma freqüência significantemente maior de LG em homens $(p=0,025)$, compatível com dados obtidos anteriormente ${ }^{(24,15)}$. Contudo, outros autores observaram predominância no sexo feminino ${ }^{(19)}$.

A pesquisa do $\mathrm{Hp}$ foi positiva em dez (67\%) LGBG e oito (47\%) LGAG. Nos últimos havia componente de linfoma MALT associado. A análise estatística desses resultados demonstrou que a infecção não foi elevada $(p=0,06)$. Também não houve diferença na presença de infecção pelo $\mathrm{Hp}$ entre os LG de alto e os de baixo grau $(p=0,276)$, e entre os positivos e negativos do grupo de baixo grau $(p=0,09)$. De acordo com alguns autores, a positividade para o Hp em LG é elevada ${ }^{(12,}$ 21), entretanto outros não encontraram altos índices de colonização pela bactéria nos casos estudados ${ }^{(16)}$. Nesses 
casos, os pacientes podem ter sido submetidos a tratamento da infecção anteriormente à gastrectomia ou à biópsia. O fato de o linfoma infiltrar a mucosa gástrica no local examinado também pode provocar resultado falso-negativo na pesquisa pelo método histológico. Outra alteração freqüentemente observada em associação com LG é a metaplasia intestinal da mucosa gástrica, que também pode prejudicar a pesquisa do $H p^{(3)}$. O fato de a positividade ser maior nos LGBG pode indicar que a bactéria está presente na fase inicial do LG e pode desaparecer com a progressão para alto grau ${ }^{(31)}$. Alguns autores postulam que a presença de $H p$ parece não ser obrigatória para transformação em alto grau ${ }^{(5)}$.

O índice proliferativo (IP), avaliado pela expressão da proteína Ki-67, foi mais alto nos LGAG. A análise estatística mostrou associação positiva entre o grau histológico e a expressão de Ki-67 $(p=0,005)$. Valores semelhantes foram observados por outros autores ${ }^{(1,37)}$. Pode ser considerado, portanto, que os LG, ao se transformarem de baixo para alto grau, adquirem características morfológicas distintas e maior índice de proliferação celular.

A utilização do anticorpo AE1/AE3 permitiu melhor visualização das lesões linfoepiteliais (LLE), ao corar estruturas epiteliais infiltradas pelo linfoma. A identificação dessas lesões no exame histológico é importante para o diagnóstico de linfoma do tipo MALT ${ }^{(27)}$, entretanto elas podem também ocorrer em linfoma folicular primário do estômago ${ }^{(35)}$. A freqüência dessas lesões nos $L G B G$ foi mais estatisticamente significante $(p<0,01)$. Parte dos LG de alto grau apresentou LLE, mesmo sem haver componente de baixo grau associado. Nesses casos observou-se infiltração e destruição de estruturas epiteliais por linfócitos grandes e atípicos, ao contrário dos LG MALT de baixo grau onde as LLE são formadas por pequenos linfócitos.

A identificação de lesões linfoepiteliais no componente MALT de baixo grau associado a LGAG é importante por constituir fator prognóstico favorável, o que permite distinguir dois subtipos histológicos desse grupo de LG. Um grupo seria o linfoma de alto grau com LLE, com bom prognóstico, e o outro, o linfoma difuso de grandes células não-associado a linfoma MALT de baixo grau, que apresenta pior prognóstico(14).

Neste trabalho foi observada expressão baixa da proteína p53 em LGBG e alta nos LGAG, diferença esta estatisticamente significante $(p<0,01)$. A perda da função do p53 é comumente causada por mutação de um alelo e perda do outro (fenômeno caracterizado como perda da heterozigosidade, defeito genético comumente encontrado em várias neoplasias humanas), o que contribui para o desenvolvimento e a progressão dessas doenças. A expressão da proteína p53 não depende somente da mutação no gene. Eventos pós-transcricionais, como a formação de complexos com proteínas celulares ou virais, podem estender a vida média da proteína p53 selvagem, resultando em superexpressão(8).

A expressão da proteína BCL-2 foi maior em LGBG. No componente de baixo grau observado em dez LGAG, a BCL-2 foi positiva, fenômeno também observado anteriormente ${ }^{(32)}$. O crescimento lento do linfoma de baixo grau poderia estar relacionado à expressão de BCL-2(11). Na transformação para alto grau, as células do linfoma podem deixar de expressar BCL-2(10).

A análise estatística da expressão inversa das proteínas p53 e BCL-2 neste estudo mostrou que há associação entre as duas variáveis $(p=0,004)$, achados compatíveis com a maioria dos trabalhos consultados, que descreveram positividade elevada da p53 nas lesões de alto grau e da BCL-2 nas de baixo grau ${ }^{(30)}$. Nos linfomas LGBG que sofrem transformação para alto grau tende a ocorrer correlação inversa entre a expressão de BCL2 e p53. A positividade da proteína p53 aumenta quando a positividade da proteína $\mathrm{BCL}-2$ diminui e o grau histológico avança. Esses resultados sugerem que a expressão de BCL-2 e de p53 participa da transição de tumores de baixo para alto grau $^{(10)}$. Mutações nesses genes podem alterar o índice apoptótico e proliferativo das células ${ }^{(29)}$.

A diferença de expressão da proteína BCL- 6 entre os grupos de baixo e alto grau não foi significante $(p=0,67)$, resultado não-concordante com o de outros autores que encontraram freqüência significantemente maior de resultados negativos em linfomas de baixo grau ${ }^{(17)}$.

A demonstração da expressão alterada dos genes p53, BCL-2 e BCL-6 em cortes histológicos permite supor que ocorre participação deles na patogênese dos LG, entretanto a relação entre eles e os mecanismos pelos quais esses genes atuam ainda não estão esclarecidos. Da mesma forma, não está totalmente esclarecida a participação da bactéria Helicobacter pylori na gênese dessas neoplasias, a qual pode não ser identificada rotineiramente em parte dos casos, no momento do diagnóstico. 


\section{Referências}

I. ARENDS, J. E. et al. Expression of CDIO and CD43 in MALT lymphoma and their usefulness in discriminating MALT lymphoma from follicular lymphoma and chronic gastritis. Histopathology, v. 35, p. 209-15, 1999.

2.ARIMA, N.;TSUDO, M. Extragastric mucosa-associated lymphoid tissue lymphoma showing the regression by Helicobacter pylori eradication therapy. Br J Haematol, v. 120, n. 5, p. 790-2, 2003.

3. ARISTA-NASR, J. et al. Histology changes of the gastric mucosa associated with primary gastric lymphoma in endoscopic biopsy specimens. Arch Pathol Lab Med, v. 124, p. 1628-31, 2000.

4. BOOT, H.; de JONG D. Gastric lymphoma: the revolution of the past decade. Scand J Gastroenterol Suppl, v. 236, p. 27-36, 2002.

5. BOUZOURENE, H. et al. Aberrant crypt foci in patients with neoplastic and nonneoplastic colonic disease. Hum Pathol, v. 30, p. 66-7I, 1999.

6. CALETTI, G. et al. Consecutive regression of concurrent laryngeal and gastric MALT lymphoma after anti-Helicobacter pylori therapy. Gastroenterology, v. I24, n. 2, p. 537-43, 2003.

7. CATTORETTI, G. et al. BCL-6 protein is expressed in germinalcenter B cells. Blood, v. 86, n. I, p. 45-53, 1995.

8. COGLIATTI, S. B. et al. Significantly different bcl-2 expression profiles in gastric and non-gastric primary extranodal highgrade B-cell lymphomas.J Pathol, v. 192, p. 470-8, 2000.

9. DIERLAMM, J. et al. BCL-6 gene rearrangements also occur in marginal zone B-cell lymphoma. Br J Haematol, v. 98, n. 3, p. 719-25, 1997.

10. DOGUSOY, G. et al. Histopathologic features and expression of BCL-2 and p53 proteins in primary gastric lymphomas. Pathol Oncol Res, v. 5, p. 36-40, 1999.

I I. DU, M. et al. Positive correlation between apoptotic and proliferative indices in gastrointestinal lymphomas of mucosa-associated lymphoid tissue (MALT).J Pathol, v. 178, p. 379-84, 1996

12. ECK, M. et al. MALT-type lymphoma of the stomach is associated with Helicobacter pylori strains expressing the CagA protein. Gastroenterology, v. I I 2, n. 5, p. I482-6, 1997.

I 3. EIDT, S.; STOLTE, M.; FISCHER, R. Helicobacter pylori gastritis and primary gastric non-Hodgkin's lymphomas. J Clin Pathol, v. 47, p. 436-9, 1994.

14. FERRERI,A. J. et al. Prognostic significance of the histopathologic recognition of low- and high-grade components in stage I-II B-cell gastric lymphomas. Am J Surg Pathol, v. 25, n. I, p. 95-102, 2001.

15. FISCHBACH,W. et al. Primary gastric B-cell lymphoma: results of a prospective multicenter study. Gastroenterology, v. I 19, p. I | 9 |-202, 2000.

16. FISCHBACH,W. Gastrointestinal lymphomas: the Würzburg study experience. Recent Results Cancer Res, v. I56, p. I34-40, 2000.

17. GAIDANO, G. et al. Frequent mutation of BCL-6 protooncogene in high grade, but not low grade, MALT lymphomas of the gastrointestinal tract. Haematologica, v. 84, p. 582-8, 1999.
18. HARRIS, N. L.; STEIN, H.; BANKS, P. M. A revised EuropeanAmerican classification of lymphoid neoplasms: a proposal from the International Lymphoma Study Group. Blood, v. 84, p. I 36|-92, 1994.

19. HIYAMA, T.et al. Clinicopathological features of gastric mucosaassociated lymphoid tissue lymphoma: a comparison with diffuse large B-cell lymphoma without a mucosa-associated lymphoid tissue lymphoma component. J Gastroenterol Hepatol, v. I6, p. 734-9, 2001.

20. HJELMSTROM, P. Lymphoid neogenesis: de novo formation of lymphoid tissue in chronic inflammation through expression of homing chemokines.J Leukoc Biol, v. 69, p. 331-9, 2001.

21. HUNGRIA, V.T. M. et al. Helicobacter pylori associado a linfoma gástrico primário tipo MALT. Bol Soc Bras Hematol Hemoter, v. 16, p. 279-81, 1994.

22. ISAACSON, P. G.; SPENCER, J. Gastric lymphoma and Helicobacter pylori. Important Adv Oncol, p. I I I-2 I, 1996.

23. ISAACSON, P. G. Gastric MALT lymphoma: from concept to cure. Ann Oncol, v. 10, p. 637-45, 1999.

24. KATH, R. et al. Primary gastric non-Hodgkin's lymphoma: a clinical pathological study of 4 I patients. J Cancer Res Clin Oncol, v. |21, p. 51-6, 1995.

25. KELESSIS, N. G. et al. Is gastroscopy still a valid diagnostic tool in detecting gastric MALT lymphomas? A dilemma beyond the eye. Mucosa-associated lymphoid tissue. Surg Endosc, v. 17, n. 3, p. 469-74, 2003.

26. KWON, M. S. et al. Critical evaluation of BCL-6 protein expression in diffuse large B-cell lymphoma of the stomach and small intestine. Am J Surg Pathol, v. 27, n. 6, p. 790-8, 2003.

27. LEWIN, K. J.; APPLEMAN, H. D. Tumors of the esophagus and stomach. Washington, D.C.: Armed Forces Institute of Pathology, 1995.

28. McDONNELL, T. J. et al. The BCL-2 oncogene: apoptosis and neoplasia. Radiat Res, v. I36, n. 3, p. 307- 12, 1993.

29. MULLAUER, L. et al. Mutations in apoptosis genes: a pathogenetic factor for human disease. Mutat Res, v. 488, p. 21 I-31, 2001 .

30. NAKAMURA, S. et al. Inverse correlation between the expression of $\mathrm{BCL}-2$ and $\mathrm{p} 53$ proteins in primary gastric lymphoma. Hum Pathol, v. 27, p. 225-33, 1996.

31. NAKAMURA, S. et al. Helicobacter pylori and primary gastric lymphoma. A histopathologic and immunohistochemical analysis of 237 patients. Cancer, v. 79, p. 3-I I, 1997.

32. NAVRATIL, E. et al. Expression of the BCL-2 protein in B-cell lymphomas arising from mucosa-associated lymphoid tissue. J Clin Pathol, v. 48, p. 18-21, 1995.

33. RANALDI, R. et al. A clinicopathological study of I 52 surgically treated primary gastric lymphomas with survival analysis of 109 high grade tumours. J Clin Pathol, v. 55, p. 346-5I, 2002.

34.THIEDE, C. et al. Eradication of Helicobacter pylori and stability of remissions in low-grade gastric B-cell lymphomas of the mucosa-associated lymphoid tissue: results of an ongoing multicenter trial. Recent Results Cancer Res, v. I56, p. 12533, 2000. 
35. TZANKOV, A. et al. Primary gastric follicular lymphoma with parafollicular monocytoid B-cells and lymphoepithelial lesions, mimicking extranodal marginal zone lymphoma of MALT. Virchows Arch, v. 44I, n. 6, p. 614-7, 2002.

36. VILLUENDAS, R. et al. Different BCL-2 protein expression in high-grade B-cell lymphomas derived from lymph node or mucosa-associated lymphoid tissue. Am J Pathol, v. I39, p. 989-93, 1991.

37. WANG, P. L.; PEH, S. C. The pattern of Ki-67 and BCL-2 expression in lymphoid malignancies. Malays J Pathol, v. 19 , p. 59-64, 1997.
38.WOTHERSPOON,A. C. et al. Regression of primary low-grade B-cell gastric lymphoma of mucosa-associated lymphoid tissue type after eradication of Helicobacter pylori. Lancet, v. 342, p. 575-7, 1993.

39. WOTHERSPOON, A. C. et al. Helicobacter pylori-associated gastritis and primary B-cell gastric lymphoma. Lancet, v. 338, p. | |75-6, | $99 \mid$.

40.YOSHINO,T. et al. Clinicopathological features of gastric mucosa associated lymphoid tissue (MALT) lymphomas: high grade transformation and comparison with diffuse large B-cell lymphomas without MALT lymphoma features.J Clin Pathol, v. 53, p. $187-90,2000$. 